\title{
The utility of the enhancement techniques for mapping subsurface structures from gravity data
}

\section{Luan Thanh Pham ${ }^{1}$, Tuyen Xuan Nguyen ${ }^{2, *}$, Ahmed M. Eldosouky ${ }^{3}$, Thanh Duc Do', Toan Quoc Nguyen ${ }^{4}$}

\author{
${ }^{1}$ Faculty of Physics, University of Science, Vietnam National University, 334 Nguyen Trai, Thanh Xuan, Hanoi, Vietnam \\ ${ }^{2}$ Faculty of Basic Sciences, University of Transport and Communications, 3 Cau Giay, Dong Da, Hanoi, Vietnam \\ ${ }^{3}$ Geology Department, Faculty of Science, Suez University, Suez, 43518, Egypt \\ ${ }^{4}$ Dai Nam University, 56, Vu Trong Phung, Thanh Xuan, Hanoi, Vietnam
}

\begin{tabular}{|c|c|}
\hline ARTICLE INFO & ABSTRACT \\
\hline $\begin{array}{l}\text { Article history: } \\
\text { Received } 5 \text { September } 2021 \\
\text { Received in revised form } 13 \text { September } 2021 \\
\text { Accepted } 13 \text { September } 2021 \\
\text { Available online } 14 \text { September } 2021\end{array}$ & $\begin{array}{l}\text { An important feature in the interpretation of gravity data is the determination of the } \\
\text { edges of the density structures. There are several different enhancement techniques } \\
\text { used to achieve the edge locations. In this study, we aim to estimate the effectiveness } \\
\text { of some edge enhancement techniques such as the total horizontal gradient, analytic } \\
\text { signal, theta map, and logistic function of the total horizontal gradient in terms of their }\end{array}$ \\
\hline $\begin{array}{l}\text { Keywords } \\
\text { Gravity, } \\
\text { Edge enhancement, } \\
\text { Subsurface structures, } \\
\text { Phu Khanh basin }\end{array}$ & $\begin{array}{l}\text { tested on synthetic gravity data with and without noise. Findings show that the logistic } \\
\text { function of the total horizontal gradient performs better than other methods under } \\
\text { almost all cases. Additionally, the methods are also applied to real gravity data from } \\
\text { the Phu Khanh basin as a practical example. The results determined by the LTHG } \\
\text { technique reveals the presence of many structures with E-W, NE-SW, NNW-SSE, } \\
\text { ENE-WSW, and NNE-SSW trends in the basin. }\end{array}$ \\
\hline
\end{tabular}

\section{Introduction}

Geophysical methods have been used for many years in the determination of nature and processes of the Earth [1-7], and gravity method is one of the oldest methods used to solve this problem [8,9]. Despite the development of an increasing number of additional exploration techniques, some of which can determine geological structures with higher resolution, the gravity method has continued to be an important and sometimes crucial constraint in a wide variety of terrestrial investigations [8-10]. The gravity method can help estimate the depth and horizontal location of the geological structures [11-18]. The horizontal locations of density structures have a great effect on the understanding of mineral deposits, also the optimization of exploratory drilling operations [19-21]. These locations also play an important role in basin characterization for exploring oil and gas [22]. Edge detecting techniques can outline the lateral location of the density sources [20]. There are many methods for enhancing the lateral location of the structures, most of which are based on the horizontal and vertical gradients of the gravity anomaly [24-30]. Recently, applications of enhancement techniques to potential field data have shown great success [31-45].

\footnotetext{
* Corresponding authors at: UTC

E-mail addresses: tuyennx@utc.edu.vn (Tuyen Xuan Nguyen)
}

Some authors have developed the different techniques based on the amplitudes of the gradients of the field to detect the edges related to a known gravity anomaly [4649]. Several other authors have introduced the techniques based on the ratios of gradients of the gravity data to extract the edges of the sources [50-57]. One of the most important advantages of these techniques is that they do not need an assumption about the nature and type of the causative bodies [22].

In this study, we estimate the performance of the popular edge detection techniques such as the total horizontal gradient (THG), analytic signal (AS), theta map (THETA), and logistic function of the total horizontal gradient (LTHG). We estimate the applicability of these techniques by a gravity model with and without noise. In addition, their practical utility is also estimated on real gravity dataset from the Phu Khanh basin, Vietnam.

\section{Methods}

The total horizontal gradient (THG) is one of the most commonly used techniques for enhancing the edges of density structures. The THG of the gravity field $F$ is calculated as the following equation [47]:

$$
\mathrm{THG}=\sqrt{\left(\frac{\partial \mathrm{F}}{\partial \mathrm{x}}\right)^{2}+\left(\frac{\partial \mathrm{F}}{\partial \mathrm{y}}\right)^{2}} .
$$


Another commonly used edge detection technique, called the analytical signal (AS), which is expressed as [48]:

$$
\mathrm{AS}=\sqrt{\left(\frac{\partial \mathrm{F}}{\partial \mathrm{x}}\right)^{2}+\left(\frac{\partial \mathrm{F}}{\partial \mathrm{y}}\right)^{2}+\left(\frac{\partial \mathrm{F}}{\partial \mathrm{z}}\right)^{2}} .
$$

The partial derivatives in the THG and AS operators are easily calculated by the frequency or space techniques.

Wijns et al. (2005) suggested use of an arctan of the ratio between the horizontal gradient and the analytic signal to outline the edges of density structures, called the theta map (THETA). The method is expressed as [51]:

$$
\text { THETA }=\operatorname{acos} \frac{\sqrt{\left(\frac{\partial \mathrm{F}}{\partial \mathrm{x}}\right)^{2}+\left(\frac{\partial \mathrm{F}}{\partial \mathrm{y}}\right)^{2}}}{\sqrt{\left(\frac{\partial \mathrm{F}}{\partial \mathrm{x}}\right)^{2}+\left(\frac{\partial \mathrm{F}}{\partial \mathrm{y}}\right)^{2}+\left(\frac{\partial \mathrm{F}}{\partial \mathrm{z}}\right)^{2}}}
$$

Another edge detection filter based on the ratio of the derivatives of the THG, was proposed by Pham et al. (2019) for improving the resolution of results, called the logistic function of the total horizontal gradient, which is given by [53]:
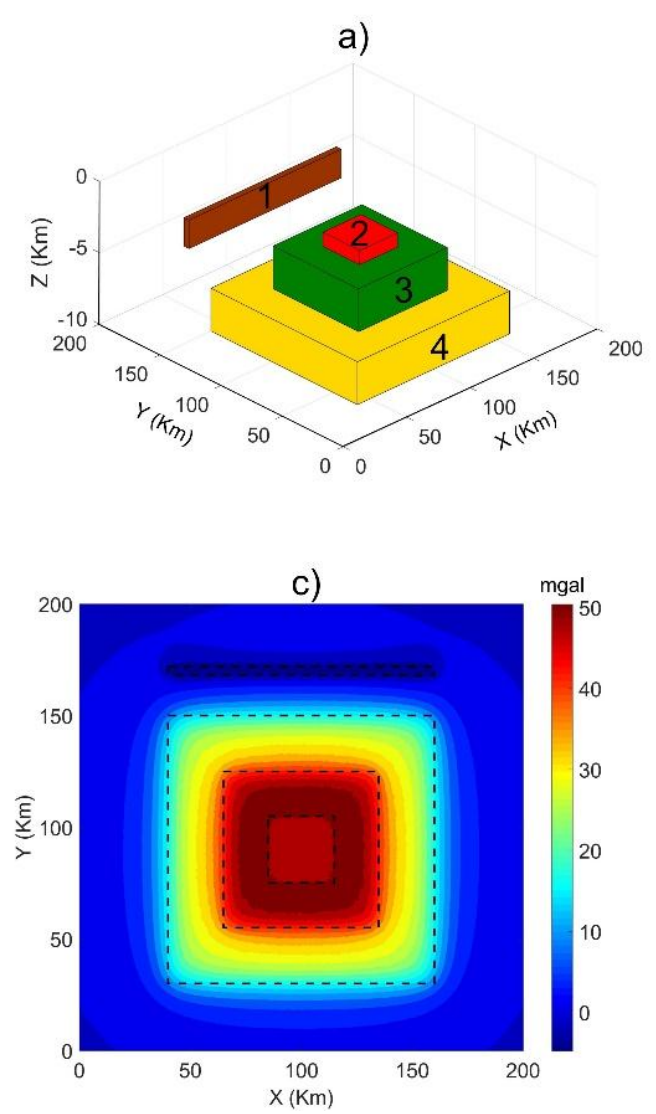

$$
L T H G=[1+\exp (-R)]^{-\infty}
$$

where

$$
R=\frac{\frac{\partial T H G}{\partial z}}{\sqrt{\left(\frac{\partial T H G}{\partial x}\right)^{2}+\left(\frac{\partial T H G}{\partial y}\right)^{2}}}
$$

and $\alpha$ is a constant that is decided by the researcher. This constant controls the effectiveness of the method. Pham et al. (2019) shows that the best results were obtained when using $\alpha=2 \sim 10$ [53]. The main attributes of the LTHG operator are to provide maximal amplitudes on the horizontal boundaries of the sources and equalize signals from shallow and deep structures.

\section{Synthetic model}

To estimate the effectiveness of the techniques, we constructed a synthetic gravity model that includes four prismatic sources with the parameters are presented in Table 1. Fig. 1a shows the 3D view of the model. The gravity anomaly due to this model is displayed in Fig. 1b as the observed anomaly. The dashed lines in figures show the true boundaries of the prismatic sources.
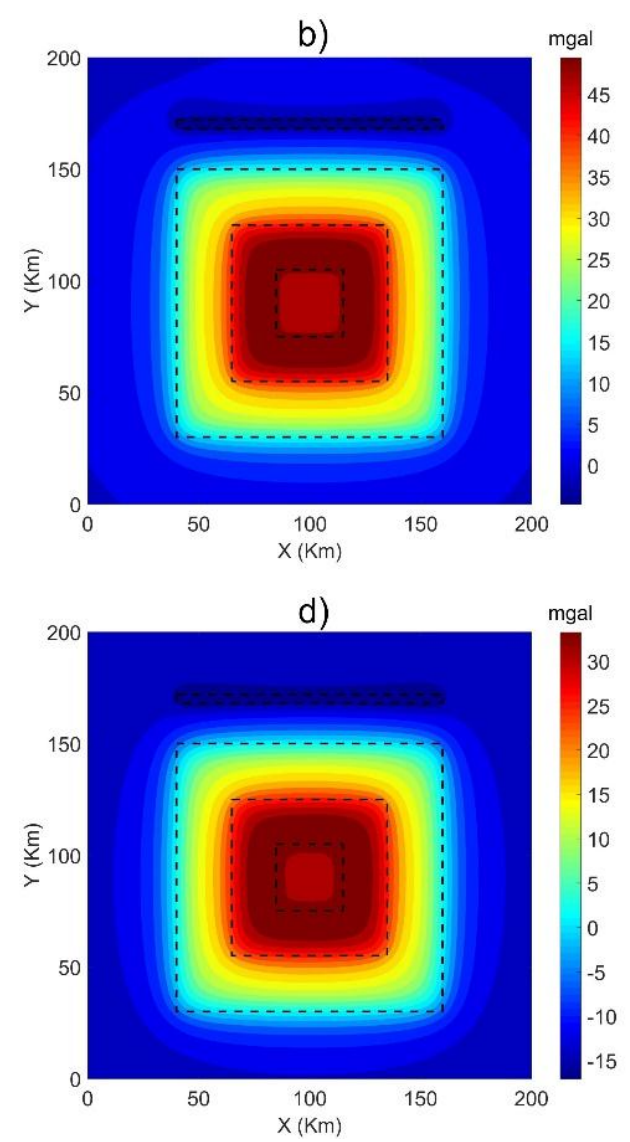

Fig. 1. (a) 3D view of the model, (b) gravity anomaly of the model without random noise, (c) gravity anomaly of the model with $2 \%$ random noise, (d) noise gravity anomaly after upward continuation of $1.5 \mathrm{~km}$. 
Table 1. Parameters of the synthetic model

\begin{tabular}{ccccc}
\hline Parameters & $\mathbf{1}$ & $\mathbf{2}$ & $\mathbf{3}$ & $\mathbf{4}$ \\
\hline x- coordinates of center $(\mathrm{km})$ & 100 & 100 & 100 & 100 \\
$\mathrm{y}$ - coordinates of center $(\mathrm{km})$ & 170 & 90 & 90 & 90 \\
Width $(\mathrm{km})$ & 4 & 30 & 70 & 120 \\
Length $(\mathrm{km})$ & 120 & 30 & 70 & 120 \\
Depth of top $(\mathrm{km})$ & 3 & 3 & 4 & 7 \\
Depth of bottom $(\mathrm{km})$ & 5 & 4 & 7 & 10 \\
Excess contrast $\left(\mathrm{g} / \mathrm{cm}^{3}\right)$ & -0.2 & 0.2 & 0.3 & -0.3 \\
\hline
\end{tabular}

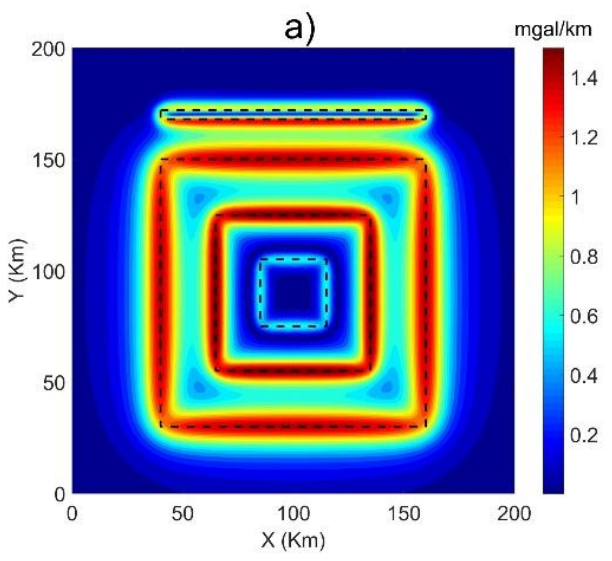

c)

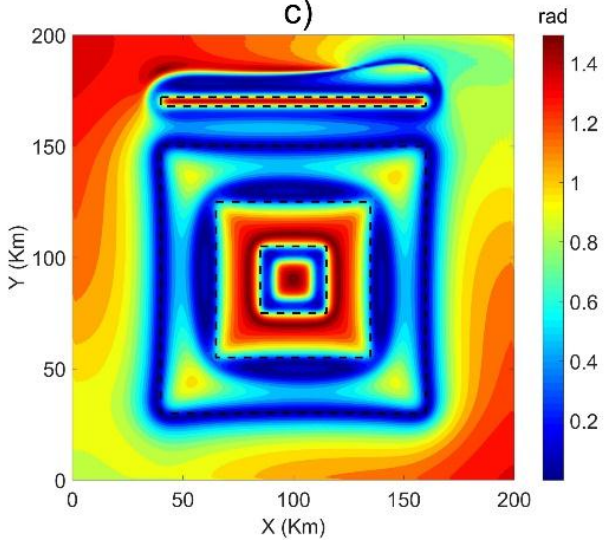

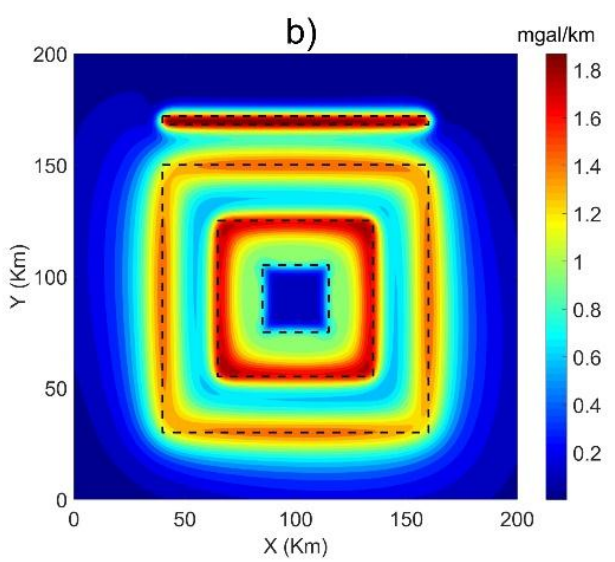

d)

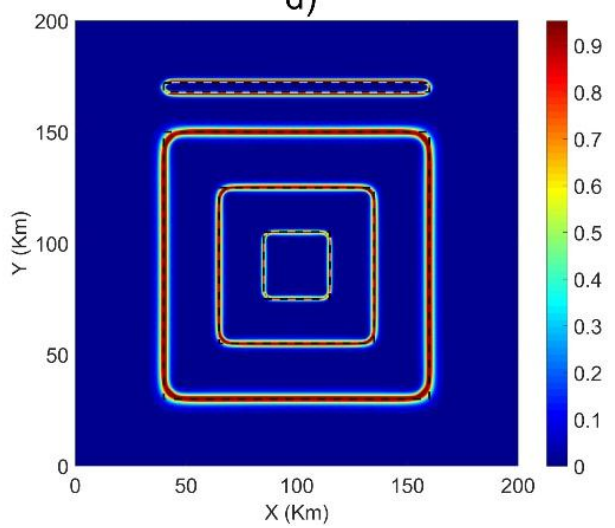

Fig. 2. Edge detection results for the gravity data in Fig. 1b. (a) THG, (b) AS, (c) THETA, (d) LTHG.

In first case, we applied the THG, AS, THETA, and LTHG methods to the gravity data in Fig. 1b. Fig. 2a shows the edges outlined by the THG method. We can see that this method can detect the edges of the sources 1,3 and 4 , but the responses from the source 2 are blurred. Fig. $2 b$ displays the edges outlined by the AS technique. Similar to the THG method, the AS is less effective in detecting the edges of the body 2, and it cannot extract the boundaries of the body 1 . In addition, the boundaries obtained from these methods are relatively diffuse. Fig. $2 c$ displays the edges estimated by the THETA technique. As clearly observed, the technique cannot detect the edges of the bodies 1, 2 and 3. Moreover, this method brings false edges around sources 1 and 3 . Fig. $2 d$ displays the edges extracted by the LTHG technique. We can see from this figure that the LTHG technique provides excellent estimates of all the edges of the sources, and the edges extracted by this method are clearer and more accurate than those determined by other techniques.

To further estimate the stability of the techniques, we consider the second case. Here, the gravity anomaly in Fig. $1 \mathrm{~b}$ was added with random noise with amplitude equal to $2 \%$ of the amplitude of the anomaly. Fig. 1c displays the noise-corrupted gravity anomaly. Because the edge enhancement techniques are based on the gradients of the gravity data, they may amplify the noise signals in the data. An upward continuation filter of $1.5 \mathrm{~km}$, was applied to the noise data before application of the techniques to reduce the noise effect. Fig. 3a displays the edges determined by the THG method. As can be seen, the method can extract the edges of the sources 3 and 4 , but it is less effective for the sources 1 and 2. Fig. $3 b$ displays the result determined by the AS method. The method brings the maxima over the 
edges of the sources 2, 3 and 4, but for thin source 1, it peaks are positioned directly over the body center. In this case, the THG and AS method also cannot bring the edges with high resolution. Fig. $3 \mathrm{c}$ depicts the edges estimated by the THETA method. Again, this technique cannot detect the edges of the sources 1 and 3 , and it also produces

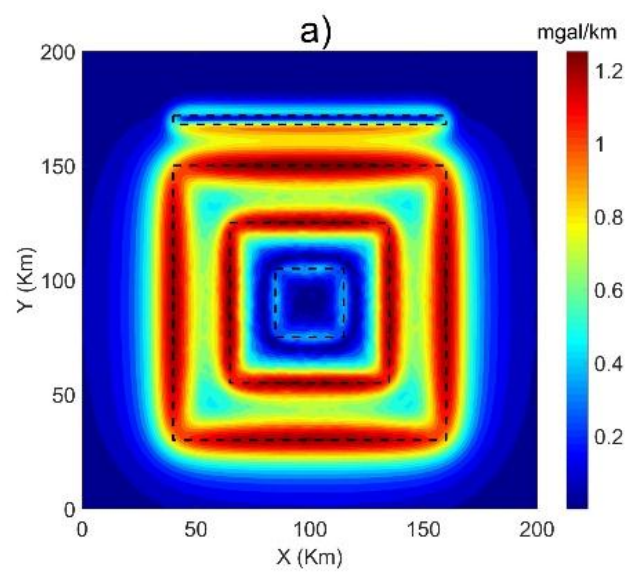

c)

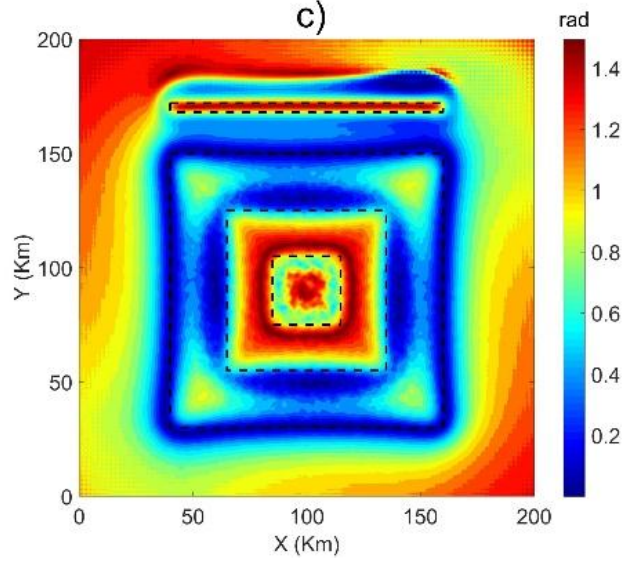

Fig. 3. Edge detection results for the gravity data in Fig. 1d. (a) THG, (b) AS, (c) THETA, (d) LTHG. false edges around these sources. Fig. $3 d$ depicts the edges determined by the LTHG technique. Clearly, this technique is able to extract all the edges and also can avoid bringing false edges. Moreover, the LTHG produces an image with higher resolution than other methods.

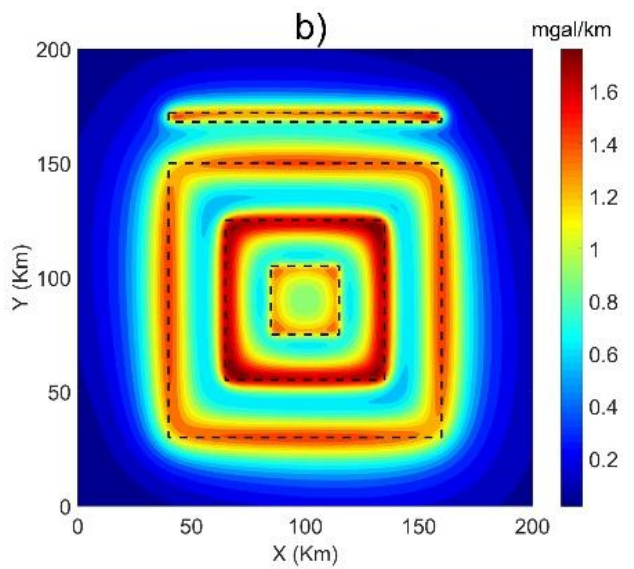

d)

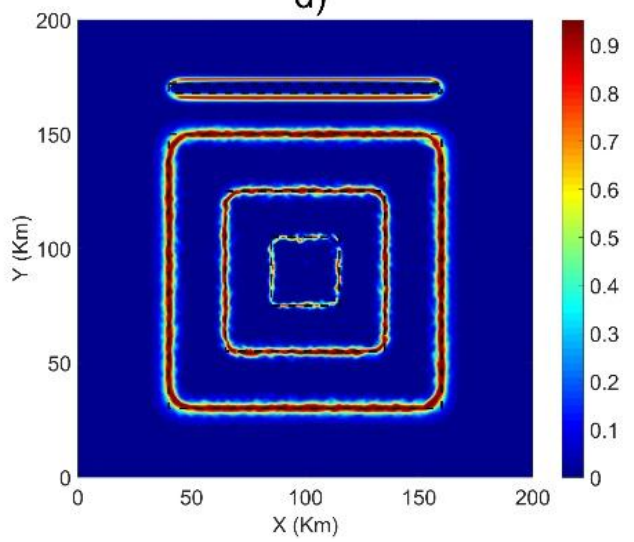

shows the Bouguer gravity anomaly of the area [59]. To reduce the effect of the noise, an upward continuation filter of $5 \mathrm{~km}$ was applied to the Bouguer gravity anomalies before calculating the edge detection functions. Fig. 5b displays the gravity anomalies after the upward continuation of $5 \mathrm{~km}$.

Fig. 6a displays the results obtained from using the THG technique. As can be seen, the THG is dominated by anomalies in the southwestern region, which may be generated by the shallow structures. Fig. $6 b$ displays the result determined by using the AS method. Similar to the THG, the AS is also dominated by anomalies in the southwestern region. As can be observed from Fig. $6 a$ and $6 \mathrm{~b}$, both the THG and AS methods are very less effective in bringing clear edges for the subsurface structures of the Phu Khanh basin. Fig. $6 \mathrm{c}$ and $6 \mathrm{~d}$ show the results determined by the THETA and LTHG techniques. We can see that the THETA and LTHG are very effective in balancing the amplitudes of anomalies, and these methods have much sharper gradients over the source boundaries than the THG and AS methods. 


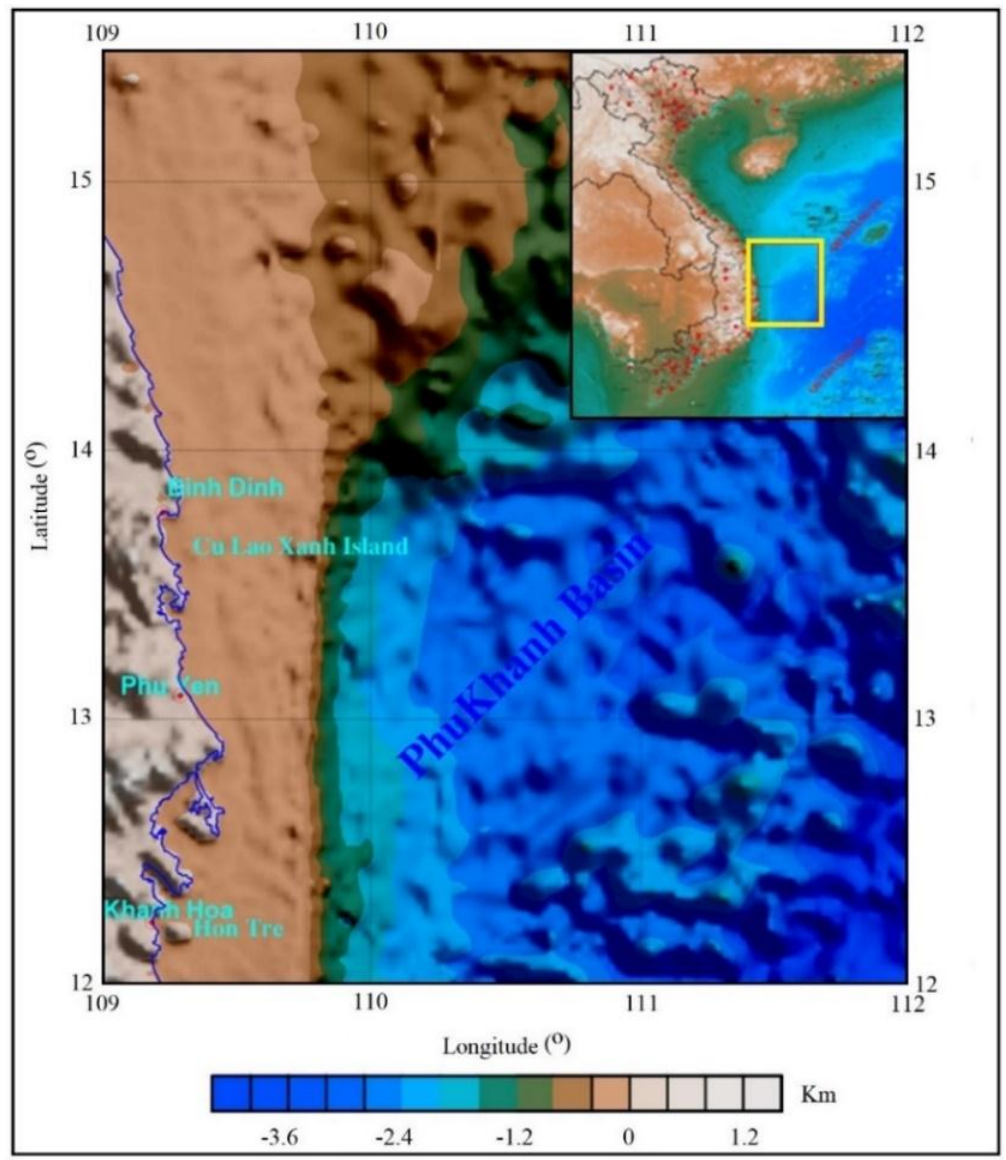

Fig. 4. Location and bathymetry maps of the Phu Khanh basin (modified from Kha et al., 2018 [14]).
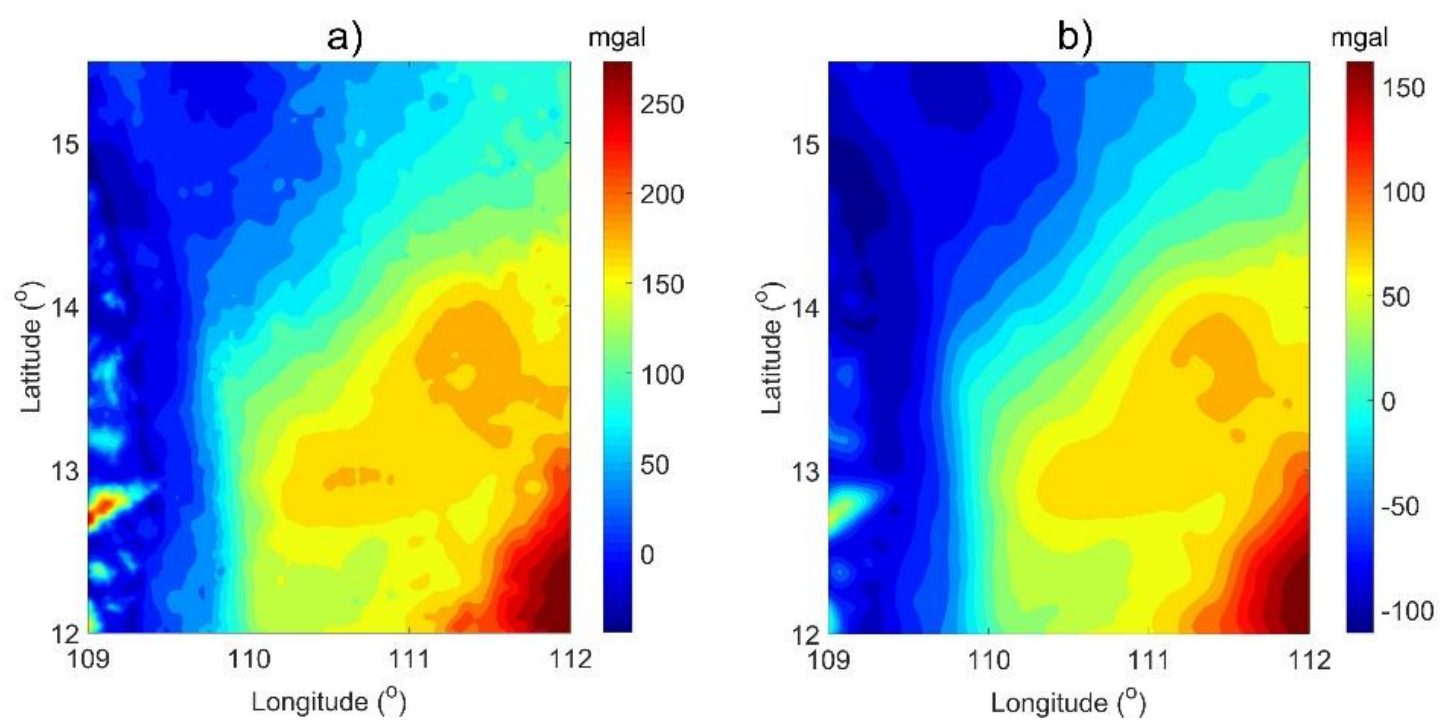

Fig. 5. (a) Bouguer gravity data of the Phu Khanh basin, (b) Bouguer gravity data upward-continued to $5 \mathrm{~km}$. 


\section{Discussion}

As can be seen from Fig 6c, although the THETA technique is effective in producing a balanced map, many adjacent edges are connected. This may lead to misleading structure interpretations. Moreover, as shown in the synthetic examples, the THETA method gives rise to artifacts in the edge maps, complicating the geological interpretation. On the other hand, it can be observed from Fig. $6 \mathrm{~d}$ that the LTHG provides excellent estimated of all the edges of the different anomalies, and the structures estimated by this method are clearer than those detected from the THETA and other techniques. Clearly, the LTHG method is effective in detecting a wide range of density structures in the Phu Khanh basin. As discussed in the synthetic examples, the LTHG method cannot only delineate edges of the shallow and deep structures at the same time, but also do not produce any spurious lateral boundaries. The results obtained from this method reveals the presence of the structures trending in E-W, NE-SW,
NNW-SSE, ENE-WSW, and NNE-SSW directions. The results agree very well with the structures reported by Kha et al. (2018) [14]. Seismic stratigraphic and structural analyses of the basin using $2 \mathrm{D}$ seismic data, indicate that the initial rifting began during the latest Cretaceous or Palaeogene, and controlled by left-lateral transtension along the East Vietnam boundary fault zone and NW-SE directed extension east of the zone [58]. In the eastern region of the basin, the northeast-striking extensional LTHG boundaries present a good correlation with the faults reported by Fyhn et al. (2009) [58], which may suggest that slab-pull forces, related to the subduction of the protoSouth China Sea, controlled the extension during the initial rift phase. In addition, it is worth noting that the LTHG method provides structure boundaries with higher resolution compared to other methods. This result illustrates the usefulness of the LTHG filter for interpretation of gravity data.

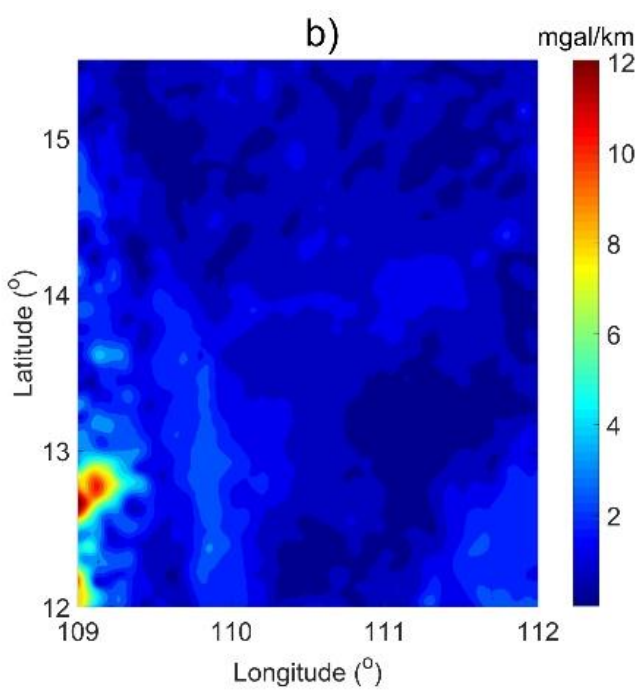

d)

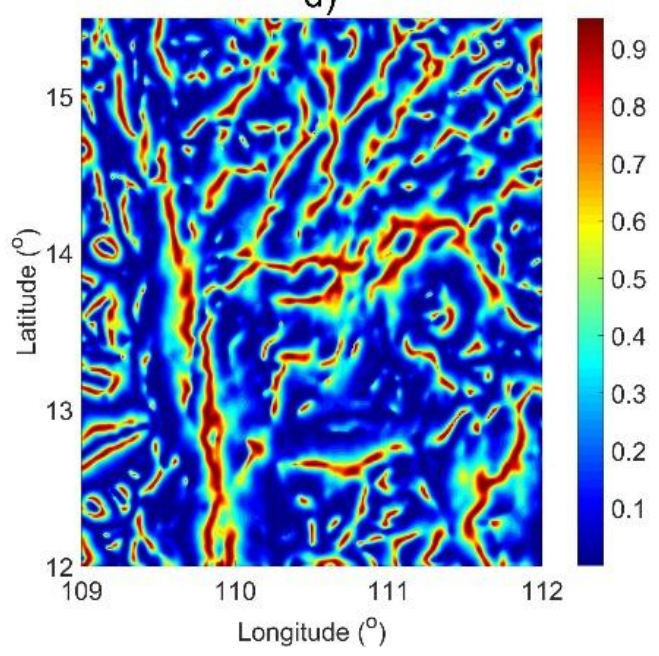

Fig. 6. Edge detection results for gravity data in Fig. 5b. (a) THG, (b) AS, (c) THETA, (d) LTHG. 


\section{Conclusion}

We have estimated the performance of the different techniques in extracting the horizontal boundaries of the density sources. The accuracy and effectiveness of these techniques were tested on both noise-free and noisy gravity data. Findings showed that the THG and AS are dominated by large amplitude due to the shallow structures, but these techniques perform poorly in detecting the boundaries of the deep structures. The results also showed that the THETA and LTHG can balance the weak and strong signals at the same time. However, the LTHG can avoid bringing false infomation in the edge maps, and it produces the edges with higher resolution compared to the THETA and others. The methods were also applied to gravity data from the Phu Khanh basin to obtain the edge images of the subsurface structures in the region. In this case, the LTHG method is also more effective in extracting the edges than other filters. The LTHG map shows many structures with E-W, NE-SW, NNW-SSE, ENE-WSW, and NNE-SSW trends in the Phu Khanh basin.

\section{Acknowledgments}

This research is funded by University of Transport and Communications (UTC) under grant number T2021-CB005. The authors sincerely thank Assoc. Prof. Vu Duc Minh from VNU University of Science, for his very useful suggestions for improving the manuscript.

\section{References}

[1] Vu, M.D, Xayavong, V., Do, C.A, Pham, L.T, GómezOrtiz, D., Eldosouky, A.M. (2021). Application of the improved multi-electrode electrical exploration methods for groundwater investigation in Vientiane Province, Laos. Journal of Asian Earth Sciences: X 5, 100056.

[2] Liem, N.V., Trinh, P.T., Phong, T.V., Lien, V.T.H., Huong, N.V., Xuyen, N.Q., Thanh, B.N., Hao, D.V., Pham, B.T., Dung, N.V., Dang, V.K., An, V.H. (2021). Pliocene - present tectonics and strain rate in Ninh Thuan region and surrounding continental shelf. Vietnam Journal of Earth Sciences 43(1), 33-56.

[3] Rugarli, P., Vaccari, F., Panza, G. (2019). Seismogenic nodes as a viable alternative to seismogenic zones and observed seismicity for the definition of seismic hazard at regional scale. Vietnam Journal of Earth Sciences 41(4), 289-304.

[4] Bela, J., Panza, G. F. (2021). NDSHA - The New Paradigm for RSHA - An Updated Review. Vietnam Journal of Earth Sciences 43(2), 111-188.

[5] Duong T.N., Lai, P.H., Pham, D.N., Chen, C.H., Dinh, V.T. (2021). Relationship between seismicity and active faults in Thanh Hoa province detected by local seismic network. Vietnam Journal of Earth Sciences 43(2), 199-219.

[6] Hang, N.T.T., Oksum, E., Minh, L.H., Thanh, D.D. (2019). An improved space domain algorithm for determining the 3-D structure of the magnetic basement. Vietnam Journal of Earth Sciences 41(1), 69-80.

[7] Rugarli, P., Vaccari, F., Panza, G. (2019). Seismogenic nodes as a viable alternative to seismogenic zones and observed seismicity for the definition of seismic hazard at regional scale. Vietnam Journal of Earth Sciences 41(4), 289-304.

[8] Hinze, W., Frese, R., Saad, A. (2012). Gravity and magnetic exploration, Principles, practices and applications. Cambridge University Press, Cambridge, p. ix.
[9] Pham L.T., Do T.D., Vu M.D., Oksum, E. (2020). Some new magnetic and gravity data interpretation methods for studying the Earth's crust. Vietnam National University, Hanoi, (in Vietnamese).

[10] Nabighian, M.N., Ander, M.E., Grauch, V.J.S., Hansen, R.O., LaFehr, T.R., Li Y., et al. (2005). Historical development of the gravity method in exploration. Geophysics 70(6), 63-89.

[11] Saada, A.S., Eldosouky, A.M., Abdelrahman, K., Al-Otaibi, N., Ibrahim, E., Ibrahim, A., 2021. New insights into the contribution of gravity data for mapping the lithospheric architecture, Journal of King Saud University - Science, 33, 101400.

[12] Pham, L.T., Do, T.D. (2017). Estimation of sedimentary basin depth using the hybrid technique for gravity data, VNU Journal of Science: Mathematics - Physics 33, 48-52.

[13] Oksum, E. (2021). Grav3CH_inv: A GUI-based MATLAB code for estimating the 3-D basement depth structure of sedimentary basins with vertical and horizontal density variation, Computers \& Geosciences 155, 104856.

[14] Kha, V.T., Vuong, V.H., Thanh, D.D., Hung, Q.D., Anh, D.L. (2018). Improving a maximum horizontal gradient algorithm to determine geological body boundaries and fault systems based on gravity data. J. Appl. Geophys. 152, 161-166.

[15] Pham, L.T., Oksum, E., Do, T.D. (2018). GCH_gravinv: A MATLAB-based program for inverting gravity anomalies over sedimentary basins. Computers \& Geosciences 120, 40-47.

[16] Oksum, E., Dolmaz, M.N., Pham, L.T. (2019). Inverting gravity anomalies over the Burdur sedimentary basin, SW Turkey. Acta Geodaetica et Geophysica 54, 445-460.

[17] Pham, L.T., Oksum, E., Dolmaz, M.N. (2021). GRV_D_inv: A graphical user interface for 3D forward and inverse modeling of gravity data. Geofizicheskiy Zhurnal 43(1), 181-193.

[18] Pham, L.T., Do, T.D., Oksum, E., Le, S.T. (2019) Estimation of Curie point depths in the Southern Vietnam continental shelf using magnetic data. Vietnam Journal of Earth Sciences 41(3), 216-228.

[19] Pham, L.T., Oksum, E., Nguyen, D.V., Eldosouky, A.M. (2021). On the performance of phase-based filters for enhancing lateral boundaries of magnetic and gravity sources: a case study of the Seattle Uplift. Arabian Journal of Geosciences 14, 129.

[20] Pham, L.T. (2020). A comparative study on different filters for enhancing potential field source boundaries: synthetic examples and a case study from the Song Hong Trough (Vietnam). Arab. J. Geosci. 13, 723.

[21] Pham, L.T. (2021). A high resolution edge detector for interpreting potential field data: A case study from the Witwatersrand basin, South Africa. Journal of African Earth Sciences 178, 104190

[22] Pham, L.T., Vu, M.D., Le, S.T. (2021). Performance Evaluation of Amplitude- and Phase-Based Methods for Estimating Edges of Potential Field Sources. Iran J Sci Technol Trans Sci. 45, 1327-1339.

[23] Melouah, O., Pham, L.T. (2021). Improved ILTHG method for edge enhancement of geological structures: application to gravity data from the Oued Righ valley. Journal of African Earth Sciences $177,104162$.

[24] Pham LT, Oksum E, Do TD, Vu MD (2021) Comparison of different approaches of computing the tilt angle of the total horizontal gradient and tilt angle of the analytic signal amplitude for detecting source edges. Bulletin of the Mineral Research and Exploration 165, 53-62. 
[25] Oksum, E., Le, D.V., Vu, M.D., Nguyen, T.H.T., Pham, L.T. (2021). A novel approach based on the fast sigmoid function for interpretation of potential field data. Bulletin of Geophysics and Oceanography. https://doi.org/10.4430/bgta0348.

[26] Pham, L.T., Nguyen, D.A., Eldosouky, A.M., Abdelrahman, K., Vu, T.V., Al-Otaibi, N., Ibrahim, E., Kharbish, S. (2021). Subsurface structural mapping from high-resolution gravity data using advanced processing methods. Journal of King Saud University - Science 33(5), 101488.

[27] Pham, L.T., Oksum, E., Vu, M.D., Vo, Q.T., Le-Viet, K.D., Eldosouky, A.M. (2021). An improved approach for detecting ridge locations to interpret the potential field data for more accurate structural mapping: a case study from Vredefort dome area (South Africa). J. Afr. Earth Sci. 175, 104099.

[28] Pham, L.T., Kafadar, O., Oksum, E., Eldosouky, A.M. (2021). An improved approach for detecting the locations of the maxima in interpreting potential field data. Arab. J. Geosci. 14, 43.

[29] Eldosouky, A.M., Pham, L.T., Mohammed, H., Pradhan, B. (2020). A comparative study of THG, AS, TA, Theta, TDX and LTHG techniques for improving source boundaries detection of magnetic data using synthetic models: a case study from G. Um Monqul, North Eastern Desert, Egypt. Journal of African Earth Sciences 170, 103940.

[30] Eldosouky, A.M., Elkhateeb, S.O., Ali, A., Kharbish, S. (2020). Enhancing linear features in aeromagnetic data using directional horizontal gradient at Wadi Haimur area, South Eastern Desert, Egypt. Carpathian J. Earth Environ. Sci. 15(2), 323-326.

[31] Narayan, S., Sahoo, S.D., Pal, S.K., Kumar, U., Pathak, V.K., Majumdar, T.J., Chouhan, A. (2017). Delineation of structural features over a part of the Bay of Bengal using total and balanced horizontal derivative techniques. Geocarto Int. 32 (4), 351- 366.

[32] Eldosouky, A.M., Elkhateeb, S.O. (2018). Texture analysis of aeromagnetic data for enhancing geologic features using cooccurrence matrices in Elallaqi area, South Eastern Desert of Egypt. NRIAG Journal of Astronomy and Geophysics 7, 155-161.

[33] Pham, L.T., Le-Huy, M., Oksum, E., Do, T.D. (2018). Determination of maximum tilt angle from analytic signal amplitude of magnetic data by the curvature-based method. Vietnam Journal of Earth Sciences 40 (4), 354-366.

[34] Eldosouky, A.M. (2019). Aeromagnetic data for mapping geologic contacts at Samr El-Qaa area, North Eastern Desert, Egypt. Arab J Geosci 12, 2.

[35] Kunnummal, P., Anand, S.P. (2019). Qualitative appraisal of high-resolution satellite derived free air gravity anomalies over the Maldives Ridge and adjoining ocean basins, Western Indian Ocean. J. Asian Earth Sci. 169, 199-209.

[36] Sehsah, H., Eldosouky, A.M. (2020). Neoproterozoic hybrid forearc - MOR ophiolite belts in the northern Arabian-Nubian Shield: no evidence for back-arc tectonic setting, Int. Geol. Rev. https://doi.org/10.1080/00206814.2020.1836523.

[37] Sehsah, H., Eldosouky, A.M., El Afandy, A.H. (2019). Unpaired ophiolite belts in the neoproterozoic allaqi-heiani suture, the arabian-nubian Shield: evidences from magnetic data, J. Afr. Earth Sci. 156, 26-34.

[38] Kumar, S., Pal, S.K., Guha, A., Sahoo, S.D., Mukherjee, A., 2020. New insights on Kimberlite emplacement around the Bundelkhand Craton using integrated satellite-based remote sensing, gravity and magnetic data. Geocarto Int. https:// doi.org/10.1080/10106049.2020.1756459.

[39] Eldosouky, A.M., Saada, S.A. (2020). Source edge detection (SED) of aeromagnetic data: synthetic examples and a case study from Haimur area, south Eastern Desert, Egypt. Arab J Geosci 13, 626.

[40] Eldosouky, A.M., Mohamed, H. (2021). Edge detection of aeromagnetic data as effective tools for structural imaging at Shilman area, South Eastern Desert, Egypt. Arab J Geosci 14, 13.

[41] Saada, A.S., Mickus, K., Eldosouky, A.M., and Ibrahim, A., 2021. Insights on the tectonic styles of the Red Sea rift using gravity and magnetic data, Marine and Petroleum Geology, 105253.

[42] Pham, L.T., Eldosouky, A.M., Abdelrahman, K., Fnais, M.S., Gomez-Ortiz, D., Khedr, F. (2021). Application of the improved parabola-based method in delineating lineaments of subsurface structures: A case study. Journal of King Saud University Science 33, 101585.

[43] Kafadar, O. (2017). CURVGRAV-GUI: a graphical user interface to interpret gravity data using curvature technique. Earth Sci. Inform. 10 (4), 525-537.

[44] Pham, L.T., Eldosouky, A.M., Melouah, O., Abdelrahman, K., Alzahrani, H., Oliveira, S.P., Peter Andrasf, P. (2021). Mapping subsurface structural lineaments using the edge filters of gravity data. Journal of King Saud University - Science. https://doi.org/10.1016/j.jksus.2021.101594,

[45] Eldosouky, A.M., Pham, L.T., El-Qassas, R.A.Y., Hamimi, Z., Oksum, E. (2021). Lithospheric Structure of the Arabian-Nubian Shield Using Satellite Potential Field Data. In: Hamimi Z., Fowler AR., Liégeois JP., Collins A., Abdelsalam M.G., Abd El-Wahed M. (eds) The Geology of the Arabian-Nubian Shield. Regional Geology Reviews. Springer, Cham. https://doi.org/10.1007/978-3030-72995-0_6.

[46] Evjen, H.M. (1936). The place of the vertical gradient in gravitational interpretations. Geophysics 1(1), 127-136.

[47] Cordell, L., Grauch, V.J.S. (1985) Mapping basement magnetization zones from aeromagnetic data in the San Juan basin, New Mexico. In: Hinze WJ (ed) The utility of regional gravity and magnetic anomaly maps. Society of exploration geophysics, 181-197.

[48] Roest, W.R.J., Verhoef, J., Pilkington, M. (1992). Magnetic interpretation using the 3-D analytic signal. Geophysics 57(1), 116-125.

[49] Beiki M. (2010). Analytic signals of gravity gradient tensor and their application to estimate source location. Geophysics 75(6), 159-174.

[50] Miller, H.G., Singh, V. (1994). Potential field tilt a new concept for location of potential field sources. J. Appl. Geophys. 32, 213-217.

[51] Wijns, C., Perez, C., Kowalczyk, P. (2005). Theta map: edge detection in magnetic data. Geophysics 70, 39-43.

[52] Pham, L.T., Do, T.D., Oksum, E. (2018). A new method for edge detection in interpretation of potential field data. Journal of Engineering Sciences and Design 6(4), 637-642.

[53] Pham, L.T., Oksum, E., Do, T.D. (2019). Edge enhancement of potential field data using the logistic function and the total horizontal gradient, Acta Geodaetica et Geophysica 54, 143-155.

[54] Yuan, Y., Yu, Q. (2014). Edge detection in potential-field gradient tensor data by use of improved horizontal analytical signal methods. Pure and Applied Geophysics 172(2), 461-472.

[55] Ma, G., Li, L. (2012). Edge detection in potential fields with the normalized total horizontal derivative. Computers \& Geosciences 41, 83-87. 
[56] Pham, L.T., Vu, T.V., Le-Thi, S., Trinh, P.T. (2020). Enhancement of potential field source boundaries using an improved logistic filter. Pure and Applied Geophysics 177, 5237524.

[57] Pham, L.T., Oksum, E., Le, D.V., Ferreira, F.J.F., Le, S.T. (2021). Edge detection of potential field sources using the softsign function. Geocarto Int. https://doi.org/ 10.1080/10106049. 2021.1882007.

[58] Fyhn, M.B.W., Nielsen, L.H, Boldreel, L.O., Thang, L.D., Bojesen-Koefoed, J., et al. (2009). Geological evolution, regional perspectives and hydrocarbon potential of the northwest Phu Khanh Basin, offshore Central Vietnam. Marine and Petroleum Geology 26, 1-24.

[59] Pham, L.T. (2020). A comparative study on different methods for calculating gravity effect of an uneven layer: Application to computation of Bouguer gravity anomaly in the East Vietnam Sea and adjacent areas. VNU J Sci Math Phys. 36(3), 106-114.

[60] Sandwell, D.T., Müller, R.D., Smith, W.H.F., Garcia, E., Francis, R. (2014). New global marine gravity model from CryoSat-2 and Jason-1 reveals buried tectonic structure. Science 346 (6205), 65-67. 